\title{
Símbolos nacionales en cambio: el caso del estandarte real de Francisco Pizarro
}

\author{
The Shifting National Symbolic: \\ The Case of the Royal Banner of Francisco Pizarro
}

DOI: https://doi.org/10.22380/20274688.1146

Recibido: 26 de enero del 2020

Aprobado: 12 de marzo del 2020

\section{LIBARDO SÁNCHEZ PAREDES* \\ Museo Nacional de Colombia \\ Isanchezp06@gmail.com}

\section{R E S U M E N}

Los símbolos sobre los cuales se cimenta el sentimiento nacional tienden a ser incuestionados. Se olvida que son productos de un proceso histórico de definición que incluye diversas interpretaciones y debates. El estandarte real atribuido a Francisco Pizarro que reposa en las colecciones del Museo Nacional de Colombia es un ejemplo paradigmático que permite apreciar las transformaciones de sentido en un objeto con el que se ha simbolizado tanto el poder real como la independencia nacional. El artículo indaga en torno a dichas transformaciones en la intención significante de este estandarte desde finales de la época colonial hasta inicios del siglo xx. El análisis muestra que el sentido del estandarte ha cambiado, obedeciendo a las tendencias ideológicas de las élites políticas en curso.

Palabras clave: estandarte de Francisco Pizarro, Museo Nacional de Colombia, símbolos nacionales

* Filósofo de la Pontificia Universidad Javeriana y magíster en Historia de la Universidad de los Andes. En la actualidad es investigador de la Curaduría de Historia del Museo Nacional de Colombia. Ha realizado múltiples exposiciones sobre temáticas históricas y ha publicado artículos sobre la historia del coleccionismo, piezas museales y sobre museología. 


\section{$\begin{array}{llllllll}\mathbf{A} & \mathbf{B} & \mathbf{S} & \mathbf{T} & \mathbf{R} & \mathbf{A} & \mathbf{C} & \mathbf{T}\end{array}$}

The symbols through which national sentiment is founded tend to be unquestioned. It is forgotten that they are products of a historical process of definition that includes various interpretations and debates. The Royal Banner attributed to Francisco Pizarro that rests in the collections of the National Museum of Colombia is a paradigmatic example that allows us to appreciate the transformations of mean- ing in an object with which both Royal power and national independence have been symbolized. The article investigates these transformations in the significant intention of this Banner from the end of the colonial period to the beginning of the 20 th century. The analysis shows that the meaning of the Banner has changed, obeying the ideological tendencies of the current political elites.

Keywords: Banner of Francisco Pizarro, National Museum of Colombia, National Symbols

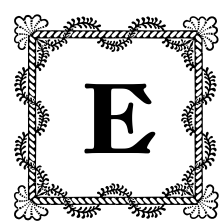

1 estandarte real de Pizarro (figura I) ha permanecido en el Museo Nacional de Colombia desde 1825, año en el que fue remitido a Bogotá por el mariscal de Ayacucho, Antonio José de Sucre (I795-I830), como un trofeo tras la finalización de las batallas de la independencia. Desde entonces, pocas piezas pertenecientes al museo han recibido tanta atención y producido tanta polémica como este insigne estandarte. Dos razones explican este hecho. La primera es simple: durante un tiempo se polemizó sobre la existencia de tres estandartes atribuidos a Pizarro: el que reposa en el Museo Nacional de Colombia, otro en Caracas y un último en Lima. Autores de distintas naciones, en algunos casos guiados por su patriotismo, atribuyeron a uno u otro estandarte la originalidad frente a los demás. Hace años, sin embargo, esta polémica ha sido zanjada y hoy nadie pone en duda que el estandarte original fue remitido a Caracas, donde actualmente reposa en el edificio de la Municipalidad (Sánchez).

La segunda razón por la cual el estandarte ha generado una copiosa bibliografía se encuentra en que hace parte de los ceremoniales políticos a partir de los cuales fue constituido un sentimiento nacional en los albores de la Independencia. Es precisamente esta problemática la que guía el presente artículo. Tal como señala Natalia Majluf, los símbolos nacionales ya consolidados tienden a ser incuestionados; se olvida que fueron producto de una transformación en su intención significante, efectuada tras diversas interpretaciones y debates (Majluf 203). Describir los diferentes significados atribuidos al estandarte 


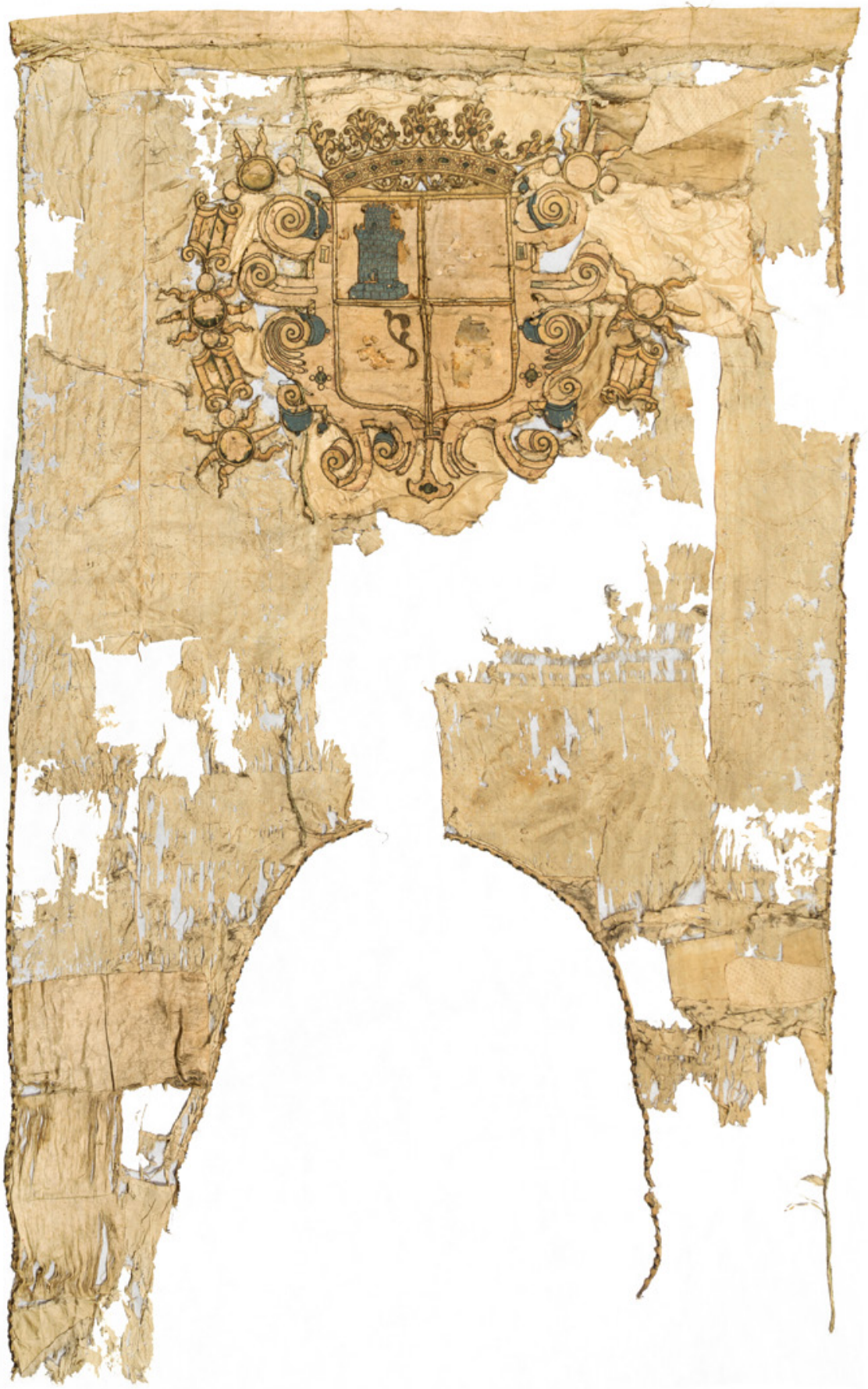

$\leftrightarrow$ FIGURA I.

Autor desconocido. Estandarte de Pizarro, ca. I529

Fuente: Museo Nacional de Colombia, registro 98. 
real de Pizarro que reposa en las colecciones del Museo Nacional de Colombia, desde finales del siglo XVIII y durante gran parte del siglo XIX, es el principal objetivo del presente artículo.

Cuando se trabaja desde la historia de los objetos, es necesario restituir los usos y las costumbres para los cuales eran utilizados. Esta labor releva el papel de personajes y situaciones que esclarecen el proceso de cambio de sentido y de identificación con su consideración cultural actual (Appadurai 17). En estos procesos de interpretación y transformación de sentido son claves, como se verá, las élites que detentaban el poder político. Siguiendo a Bourdieu, un objeto como el estandarte, con su fuerte carga simbólica, es considerado una forma de capital cultural institucionalizado, lo que implica que fue instituido como un elemento de manipulación política y económica. El estandarte, al configurarse como un valor nacional que refiere su pasado fundacional, determina los valores en los que la comunidad se reconoce y con los que a su vez define a los excluidos. De allí el poder que confiere la manipulación de su contenido simbólico (Bourdieu II).

A continuación se expone este proceso de significación y revaloración del estandarte, a partir del análisis de las situaciones en las cuales estuvo presente, enfatizando en el virreinato de la Nueva Granada durante el siglo xviII y luego en lo que hoy es Colombia durante el siglo xix. De los paseos del pendón real en la época colonial, a las procesiones cívicas en época republicana; de la autoridad del rey a la autoridad criolla y luego a las élites republicanas.

\section{El estandarte real como cuerpo presente del rey}

Durante la época colonial, el estandarte, pendón o guion real exigía para su utilización un ceremonial estricto. Según la Recopilación de leyes de los reynos de las Indias, el pendón real debía sacarse en las ciudades de América española una vez al año. El origen de las ceremonias con estandartes puede remontarse a la Edad Media. En la España visigoda era costumbre que los nobles y poderosos “alzaran el pendón” en la ceremonia de ascenso de un nuevo rey. Así se hizo también durante las coronaciones de Felipe II, Felipe III y Felipe IV (Baca 40). En América, la ceremonia inició en México y se asimiló a la fiesta de san Hipólito, convirtiéndose en una festividad conmemorativa de la conquista. La primera festividad fue promovida por Hernán Cortés (I485-I547), conquistador 
español de México, y se celebró en 528 con motivo de la conmemoración de la caída de Tenochtitlán el 13 de agosto de I52I. En la festividad se conducía el estandarte hasta la iglesia de San Hipólito, lugar en que reposaban los restos de los conquistadores muertos en la Noche Triste, el I. ${ }^{\circ}$ de julio de 520 en Tenochtitlán (Baca 7; Giraudo 9).

La ceremonia que involucraba el estandarte fue legislada por primera vez en 1535 y ratificada consecutivamente por distintos monarcas hasta Fernando VII en I8I4. Prescribía condiciones de realización estrictas que aseguraban su solemnidad. Siguiendo la ley:

En las ciudades de las Indias es costumbre usada, y guardada, sacar nuestro Pendón Real las visperas, y días señalados de cada un año, y el de Pascua de Reyes en Lima: el de San Hipólito en Mexico, le lleva un Regidor por su turno, y acompańándole, para mayor hon ra y veneración, el Virrey, Oidores, y Regimiento van a Visperas, y Missa [...]. Y porque nuestra voluntad es, que esta costumbre se continue, mandamos que los Virreyes, Presidentes, y Audiencias de nuestras Indias, en las Ciudades principales donde las huviere, asistan a esta ceremonia, como se hace en Lima y México, y lleve el Pendon el Regimiento a quien tocare por turno, desde el mas antiguo, donde no huviere Alferez Real por Nos proveído, cuyo lugar ha de ser el izquierdo del Virrey, o Presidente, porque á el derecho ha de ir el Oidor mas antiguo; y en las Ciudades donde no residiere Audiencia, le acompañen el Gobernador, Corregidor, ó Justicia mayor, y Regimiento, desde la Casa del Regidor, ó Alferez mayor que le lleva, hasta que buelva a ella; y en quanto al lugar, que ha de tener en la Iglesia, y acompañamiento, se guarde la costumbre. Y asimismo la guarden los Virreyes, Presidentes, y Ministros en acompañar a nuestro Pendon Real, y sin gravisima causa no se escusen. (Consejo de Indias, libro III, título xv, ley LVI)

El paseo del pendón, como se conocía la ceremonia a que alude la ley antes transcrita, exigía que todo el cuerpo social se presentara en pleno y desempeñara un rol particular y diferenciador de su posición en la sociedad (Albarracín I5).

En el Nuevo Reino de Granada los paseos con el estandarte real se llevaron a cabo con motivo del ciclo vital del rey, la familia real y de su representante en las Indias, el virrey. El pendón era exhibido con boato durante nacimientos, bautizos, muertes y rogativas por la salud y bienestar del rey y su familia (Albarracín I5; Pita 57 y ss.). Desde el mismo momento en que la Nueva Granada 
fue declarada virreinato en $17 \mathrm{I} 7$, el estandarte real estuvo presente en la ceremonia de entrada a Santafé de su primer virrey Jorge de Villalonga (I665-I735). El virrey exigió que para su entrada se siguiera el ceremonial tal y como se realizaba en los virreinatos de Nueva España y Perú. De este modo ingresó a la capital el 17 de diciembre de $17 \mathrm{I} 7$, conducido con un palio y portando el estandarte real (Pita I40).

La descripción de una ceremonia celebrada en Santafé con motivo del ascenso al trono de Carlos III en 1759 permite apreciar la relevancia del estandarte real durante festividades en las que el poder real se exhibía en frente de toda la comunidad. La jura de fidelidad al rey Carlos III en Santafé se realizó el 6 de agosto de $\mathbf{1 7 6 0}$, día en que se conmemoraba la fiesta de la conquista en el virreinato de la Nueva Granada (Lomne ir8). Desde el martes 5 de agosto se iluminaron las calles, en el balcón del palacio virreinal se pusieron durante tres noches "luminarias con 330 luces", todos los balcones de la plaza mayor se adornaron con damasco, "añadiéndose á esto mucha espejería, arañas y cornucopias, que ocupaban muchas luces", y construyeron para la casa de la aduana un balcón postizo en el que se ubicó una "lámina de plata del Rey" (Vargas 53).

A las 3 de la tarde del 6 de agosto

juntándose en casa del Alférez Real, D. Jorge Lozano y Peralta, todos los capitulares y muchos caballeros, en lucidos caballos y costosos jaeces y especial el dicho Alférez Real, que sacó tres caballos con muchos lacayos y negritos volantes, y dos reyes de armas vestidos de damasco carmesí, en cuya forma pasaron a Cabildo, donde estaban los Prelados de las religiones y el Sr. Provisor y Vicario general, con cuya asistencia el Escribano de Cabildo les recibió á los Alcaldes el juramento acostumbrado y al Alférez Real el pleito homenaje, y fecho, salieron al tablado que estaba frente al balcón del Sr. Virrey, y en él S. E., el Ilmo. Sr. Arzobispo, Sres. Oidores, Fiscales, Contadores y Oficiales reales, y allí, con sus dos reyes de armas, enarboló el estandarte y en alta voz dijo: “Castilla, León y las Indias por Sr. Carlos III (Q. D. G.)”. (Vargas 55)

En la ciudad de Cali, para la misma jura de Carlos III, tras el paseo del pendón el alférez real pronunció: "oídme todos - Castilla, Castilla, Castilla!, Cali, Cali, Cali!, por el Rey nuestro señor don Carlos III” (Albarracín 8).

En la ceremonia de proclamación de Carlos IV en 1790 en el Cabildo del Socorro se repitió el mismo ceremonial, con la diferencia de que allí hizo presencia el ejército de Su Majestad. Aún estaban vivos los recuerdos de la 
insurrección comunera de 178I. Tras la bendición del estandarte en la iglesia principal, la comitiva se dirigió al tablado preparado en la plaza. Allí el ejército presentó armas, luego el alférez, de rodillas

delante de un Crucifixo, y las manos sobre los Santos Evangelios dijo en altas voces: juro, reconozco, amo, y reverencio en nombre de esta villa de Nra Señora del Socorro, y su Republica por Rey, y Señor natural al Señor Don Carlos quarto el Borbon que viva felices años. (AGN, $F C, M M$, leg. II9, ff. IOOI-IO05, I790)

Luego de la jura de fidelidad se lanzaba al público una salva de monedas acuñadas para este especial propósito. Para la jura del rey Carlos IV en I789, en Santafé se repartieron monedas con la efigie del rey en el verso y el escudo de armas de la ciudad en el anverso (figura 2). De esta manera se propiciaba que el pueblo llano conociera la efigie de su nuevo rey y que a la vez se afianzara la autoridad del cabildo, representando las armas de la ciudad junto a las del monarca.

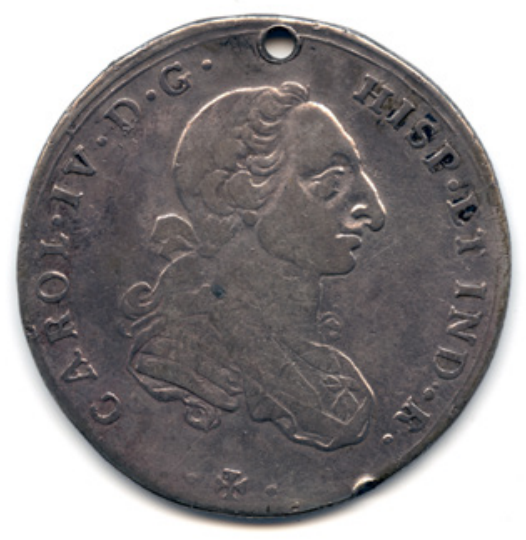

$\rightarrow$ FIGURA 2 .

Ceca Nuevo Reino de Granada. Jura real para la proclamación de Carlos IV, denominación cuatro reales, I789

Fuente: Museo Nacional de Colombia, registro I323.

En todas estas ceremonias el estandarte real era la representación del rey frente a la comunidad. El paseo del estandarte fue un ceremonial público a partir del cual dicho objeto era configurado por las élites políticas como un símbolo por excelencia de la soberanía real en el Nuevo Mundo. El cuerpo ausente del 
rey se hacía presente en el símbolo del estandarte. Asimismo, y más importante para la sociedad neogranadina, la ceremonia de la jura de fidelidad al rey era la legitimación misma de un orden social encabezado por las personalidades que podían portar el símbolo de poder, aquellas que tenían la autoridad para estar cerca del estandarte en público. El símbolo de reconocimiento de la autoridad del rey en el estandarte era la afirmación de la autoridad de la Corona española y de sus representantes en América.

\section{El estandarte real como cuerpo vencido de la monarquía española}

La victoria en las batallas por la independencia exigió también una lucha por la reconfiguración de los símbolos establecidos durante el periodo colonial que representaban el poder. De acuerdo con el historiador argentino Fabián Alejandro Campagne, la definición de una simbólica nacional en los países sudamericanos tuvo tres grandes periodos: primero, de I8IO a I830, época de consolidación de las independencias y organización de Estados nuevos; segundo, de I830 a I860, lapso en el que surgió una "corriente reflexiva, crítica y racional, que confluyó con la metafórica e icónica, prevaleciente en el ciclo anterior, a la hora de levantarse el imaginario social de las naciones en ciernes"; finalmente, los años que concluyen un largo siglo Xix que van desde la década de i860 hasta la década de 1920, periodo final del proceso de formación ideológico-simbólica de las naciones sudamericanas.

La simbólica se reprodujo en monumentos, textos literarios y una historiografía que el autor considera equiparable a la europea (Campagne y Buraca 352). Si bien la creación del sentido del estandarte real se realizó en la época colonial, este sentido se transformó, como afirma Campagne, en un primer momento al comienzo de la República, cuando el estandarte fue asociado directamente con el poder regio español. Posteriormente, cambiaría durante la segunda mitad del siglo XIX, cuando las élites políticas y económicas definieron una postura ideológica social que las acercaba a los conquistadores españoles y las alejaba del pueblo llano.

Tal y como sucedió en el periodo colonial, el sentido que la comunidad le otorgó al estandarte se devela a través del análisis de los ceremoniales públicos en los que era utilizado. Entre el is y el i6 de julio de i8I3 se reunió el Colegio Electoral en Santafé y declaró la independencia de Cundinamarca de la Corona 
de España. José María Caballero, un patriota testigo de los hechos, describió en su diario que en los días siguientes se celebraron eventos que buscaban reafirmar simbólicamente esta separación. El I9 del mismo mes se realizó un bando de la independencia, o una proclama solemne de esta. Para ello se reprodujo el ceremonial que se llevaba a cabo en las festividades regias: se adornaron las calles, se realizó un paseo de "muchos señores, ricamente vestidos y en exquisitos jaeces”, acompañados por la caballería. Al final de la ceremonia se plantó un nuevo árbol de la libertad, símbolo aportado por la Revolución francesa. Al día siguiente, el 20 de julio, se celebró la fiesta de santa Librada en la catedral. El párroco pronunció un discurso apologético de la independencia y se hizo una jura de esta:

Después se hizo el juramento de independencia; el primero que juró fue el señor presidente, en manos del secretario; y de ahí fueron jurando todas las corporaciones, prelados, eclesiásticos, colegios, síndicos y cabildos eclesiástico y secular y todos los demás. Después salieron a palacio, y mandó el señor presidente meter la bandera del batallón de Patriotas, que tenía las armas reales, y las cortaron. (Caballero I40)

En la ceremonia del paseo con el estandarte la comitiva que lo portaba ingresaba a la iglesia para su bendición. Tras la independencia, un acto de gran simbolismo consistió en el ingreso a la iglesia de los símbolos reales para su destrucción. Estos actos públicos de negación de la autoridad regia con la aniquilación de sus símbolos característicos continuaron en días sucesivos. El lunes 26 de julio los colegiales de San Bartolomé mandaron picar las armas del rey, que estaban sobre la puerta del Colegio.

Según Pedro María Ibáńez, en el mes de agosto siguiente se diseñó la nueva bandera que reemplazaría los símbolos de la monarquía. La bandera fue creada en I8I3 por el Colegio Electoral de Cundinamarca y tenía tres franjas horizontales con los colores azul celeste, amarillo tostado y rojo (Pita 202).

El martes 3I de agosto en la iglesia de San Agustín continuó el ceremonial con la nueva bandera. Allí se encontraron los oficiales de la compañía de granaderos y de artilleros. Los granaderos portaban la bandera del batallón auxiliar, que llevaba las armas del rey. Llevaban asimismo las nuevas banderas con las armas de la República para bendecirlas. Los soldados entraron a la iglesia con la solemnidad acostumbrada hasta el altar mayor, donde estaba el capellán de la tropa, el reverendo padre Florido, de la orden de San Francisco, el que hizo ciertas ceremonias para quitarle la bendición, que me hago 
el cargo que será como lo mandó el Ritual Romano. Después sacó el padre una navaja y se la dio al señor brigadier Pey, el que comenzó a hacerla tajos y rasgarla por todas partes; hecho esto la enrollaron y se la dieron al padre provincial Chaverría, el que la tiró con desprecio en el altar mayor. Se comenzó con la bendición de la nueva, que la bendijo el señor canónigo Duquesne, con las formalidades acostumbradas. Se empezó la misa, y al Evangelio toda la oficialidad se puso el sombrero y sacaron las espadas, yo fui uno de ellos, y nos estuvimos así hasta que se acabó de cantar el Evangelio; entonces envainamos las espadas y nos quitamos el sombrero. Estuvo la ceremonia muy majestuosa y lucida y respetable; concluida se regresó la nueva bandera con la pompa militar. (Caballero 144)

En I8I4, en Santafé fue cambiada la tradicional fiesta de la conquista celebrada el 6 de agosto por "la fiesta de la religión”. En la Gaceta Ministerial de Cundinamarca del II de agosto de I8I4 fue reportado que el Cabildo solicitó al Gobierno de Cundinamarca la autorización para rendir "al Estandarte del Triunfo de la Religión los mismos honores que antes se hacían al pendón real para que el pueblo por esta señal sensible venga en conocimiento del augusto objeto de la fiesta y de la santa causa que defiende" (cit. en Pita 203).

Durante la Primera República (I8IO-I8I6) el estandarte continuó siendo considerado el cuerpo presente del rey, por lo que recibió el rechazo público. Prueba de ello es que en la actualidad no se conserva el estandarte real del Virreinato de la Nueva Granada, posiblemente debido al furor de los patriotas por afirmar su identidad sobre símbolos pasados. Para anular el efecto del anterior símbolo se optó incluso por cambiar el objeto que lo portaba. Tal como señala Natalia Majluf, el cambio político implicó también el cambio del estandarte por la bandera. La sociedad colonial acostumbraba manipular los símbolos del poder regio mediante un ceremonial específico encargado a personajes primerísimos de la sociedad. La bandera en cambio podía ser portada por cualquier ciudadano y ubicarse donde se quisiera (Majluf 209-210). La bandera se adaptó al ideal republicano de una sociedad para la cual el poder, de manera ideal, no se asociaba con una persona sino con el pueblo mismo.

En los primeros años de la República, dejando a un lado las armas del rey o su efigie para representar el poder, las nuevas naciones americanas se representaron apelando al pasado que había sido negado y eligieron la figura del indígena. Buscaron relacionarse con el pasado indígena prehispánico, con aquellos 
que consideraban pueblos libres usurpados por la violencia del conquistador (Campagne y Buraca 364). La figura del indígena fue un motivo recurrente en la iconografía de las nacientes repúblicas desde México hasta Chile, una iconografía que se había desarrollado de manera temprana en México desde el siglo XVII, o en Chile en el siglo XviII (Earle 56I).

El escudo mismo de las Provincias Unidas de la Nueva Granada, creado en I815, mostraba unos arcos y unas flechas junto con la granada, símbolos del pasado indígena y de la religión católica respectivamente (figura 3). La figura del indígena fue incorporada también a otros escudos como el de Cartagena, además de la acuñación de monedas, trastocando por completo los valores que representaban las armas de la Corona española o la efigie del rey como simbólica del poder en la Nueva Granada.

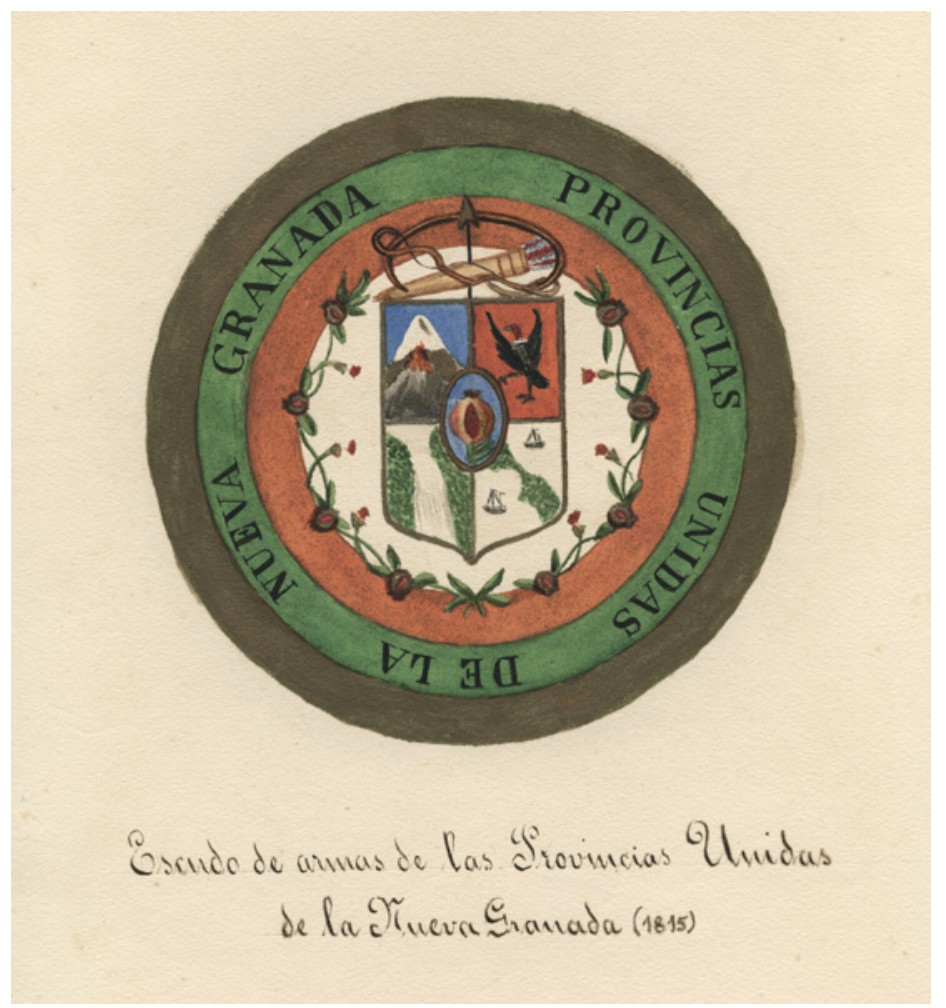

- FIGURA 3.

Liborio Zerda (I833-1919). Escudo de armas de las Provincias Unidas de la Nueva Granada (I8I5), ca. I892

Fuente: Museo Nacional de Colombia, registro 4854. 
Tal y como sucediera con el estandarte, la heráldica nacional cambiaría según las transformaciones del ideario político de las élites nacionales. En una definición posterior del escudo, las flechas, representación del indígena, se mantuvieron pero la granada, representación de la Iglesia católica, desapareció (figura 4). Finalmente, a partir de 1834, las flechas fueron eliminadas y se reincorporó definitivamente la granada (figura 5).

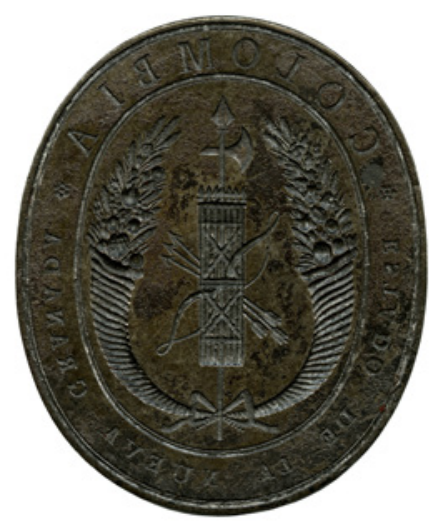

$\rightarrow$ FIGURA 4 .

Ceca de Bogotá (I620-I987). Sello del Estado de la Nueva Granada con el escudo de la República de Colombia (I8I9-I830), I83I

Fuente: Museo Nacional de Colombia, registro 809.2.

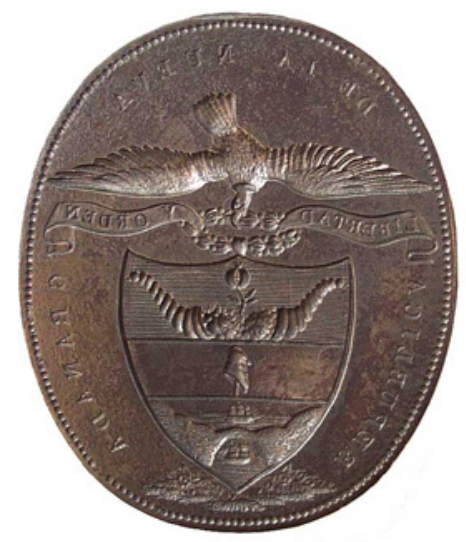

$\rightarrow$ FIGURA 5 .

Ceca de Bogotá (I620-1987). Sello con el escudo de la República de la Nueva Granada, I834

Fuente: Museo Nacional de Colombia, registro 809.I. 


\section{El estandarte de Pizarro como trofeo de guerra: su ingreso al Museo Nacional de Colombia}

Desde el momento en que el estandarte real de Pizarro llegó al Museo Nacional en I825, su donante, Antonio José de Sucre (I795-1830), expresó la consideración de que era un símbolo que representaba la victoria de los patriotas y el final del dominio de la Corona española sobre América.

Tras la victoria patriota en la Nueva Granada en I8I9, seguida por la liberación de Venezuela en I822 y de Quito en I823, Perú consiguió su independencia en I824 con las batallas de Junín en agosto y Ayacucho en diciembre de 1824. Sucre, el artífice de la victoria de Ayacucho, entró a Cuzco disfrutando de una gran fama. De la catedral tomó los estandartes reales custodiados en dicha ciudad, entre los que según la tradición se encontraba el estandarte que había portado Francisco Pizarro (I478-I54I), conquistador español del Perú, cuando entró a Cuzco en 1533.

La costumbre de capturar el estandarte enemigo era un acto simbólico que implicaba el fin de una batalla. El ejército español lo hizo en época de guerras de independencia en los actuales territorios de Argentina, Bolivia y Chile, donde las banderas de regimientos rebeldes independentistas fueron capturadas y enviadas a iglesias en ceremonias solemnes (Majluf 2I4-215). También lo hizo José de San Martín (I778-I850) tras la batalla de Maipú (Chile) el 5 de abril de I8I8, en la que capturó varias "enseñas" españolas que distribuyó a diferentes lugares. Una de estas fue enviada a Buenos Aires y recibida el 9 de marzo de I8I7 con públicos festejos (Majluf 215). O’Leary en sus memorias refiere que el mismo Simón Bolívar (1783-1830), en septiembre de I816 durante una campaña al oriente de Venezuela, "tomando la bandera del Batallón de Barlovento se puso a la cabeza de la infantería y la mandó atacar a la bayoneta” (cit. en Vanegas 69).

El contenido simbólico de estandartes y banderas estaba fuertemente establecido entre patriotas y realistas. De allí que Antonio José de Sucre escribiera a Simón Bolívar el 30 de diciembre de 1824, pocos días después de su ingreso a la ciudad de Cuzco, anunciándole que deseaba entregarle "la bandera que trajo Pizarro al Cuzco hace trescientos años pasados; son una porción de tiras desechas, pero tienen el mérito de ser la conquistadora del Perú” (O’Leary, tomo XIII, 209). Dos meses después, Sucre anunció a Bolívar que le enviaría el 
estandarte de Pizarro, además de que despacharía otras banderas al vicepresidente de Colombia, Francisco de Paula Santander (I792-I840) (O’Leary, tomo XIII, 232). Finalmente, el 23 abril de 1825 Sucre notificó el envío de todas las banderas con el coronel graduado Antonio Elizalde (I795-I862), con destino a Bogotá. Las banderas remitidas eran dos pendones reales, entre ellos el de Pizarro que debía entregarse a Bolívar (Gual; O’Leary, tomo xiıI, 249), y cinco banderas de regimientos españoles que debían permanecer en Bogotá (figuras 6, 7 y 8) (Sucre, "Perú"). En la carta de remisión de las banderas Sucre afirmaba: ellas son las señales de obediencia y estimación que el ejército le ofrece y que ruego se digne en aceptar. El estandarte con que Pizarro entró años pasados a ésta ilustre capital de los Incas lo remito a S. E. el Libertador como trofeo que corresponde al guerrero que marcó al ejército colombiano el camino de la gloria y el de la libertad del Perú. (Sucre, "Perú")

En enero de 1826 Bolívar remitió un estandarte real de Castilla con destino a Caracas, en tanto que otro quedó en Bogotá (O'Leary, tomo I, 423). Sucre consideraba las banderas un "trofeo" que

recordará un día a los hijos de los Libertadores, que sus padres, penetrados de los deberes patrios y del sublime amor a la gloria, condujeron en triunfo las armas de Colombia a las frías y eminentes cimas de Potosí. (Sucre, "Al señor secretario")

Como trofeos fueron recibidas en Bogotá las banderas que se exhibieron en el Palacio de Gobierno:

Estas banderas se conservarán en un lugar público para que a su vista los colombianos a quienes ellas pertenecen ya, se trasladen con la imajinacion a los afortunados campos de Ayacucho y sean testigos del heroismo del ejército de sus compatriotas. (Gual I825) 


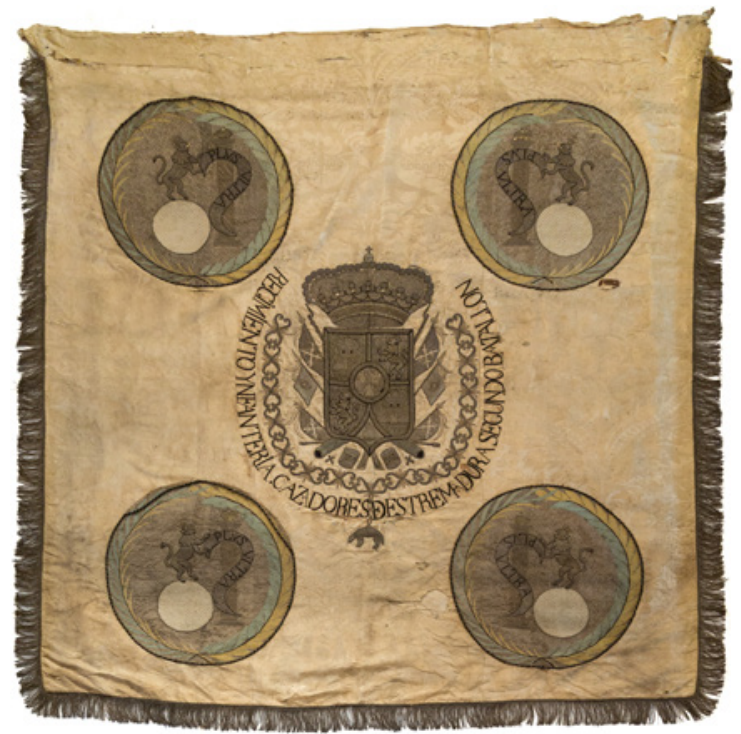

$\rightarrow$ FIGURA 6.

Autor desconocido. Bandera española del regimiento de infantería de los Cazadores de Extremadura, segundo batallón, tomada en la campaña de Independencia del Perú, ca. I8I5

Fuente: Museo Nacional de Colombia, registro ıoo.

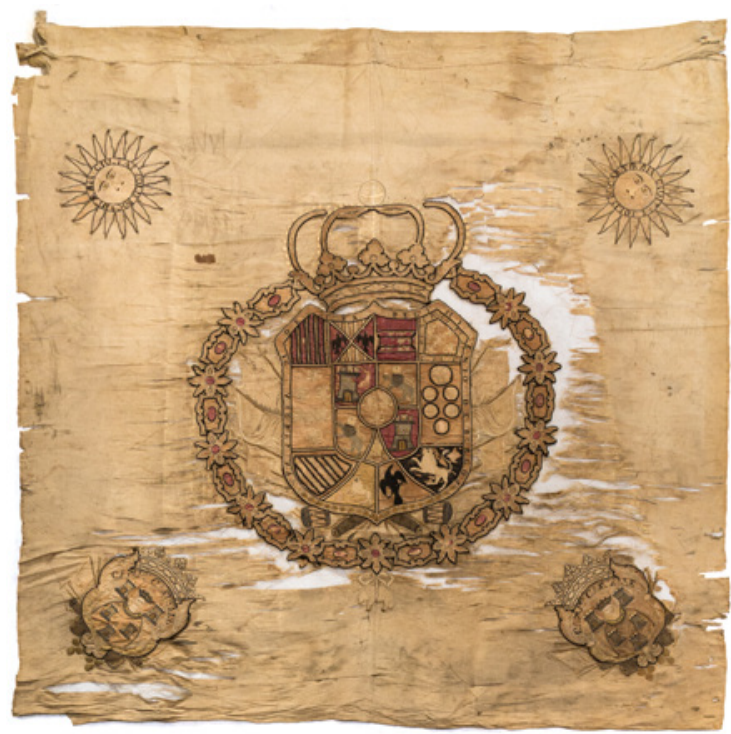

$\rightarrow$ FIGURA 7 .

Autor desconocido. Bandera coronela española del Regimiento de Burgos, tomada en la campaña de independencia del Perú, ca. I8I5

Fuente: Museo Nacional de Colombia, registro IOI 


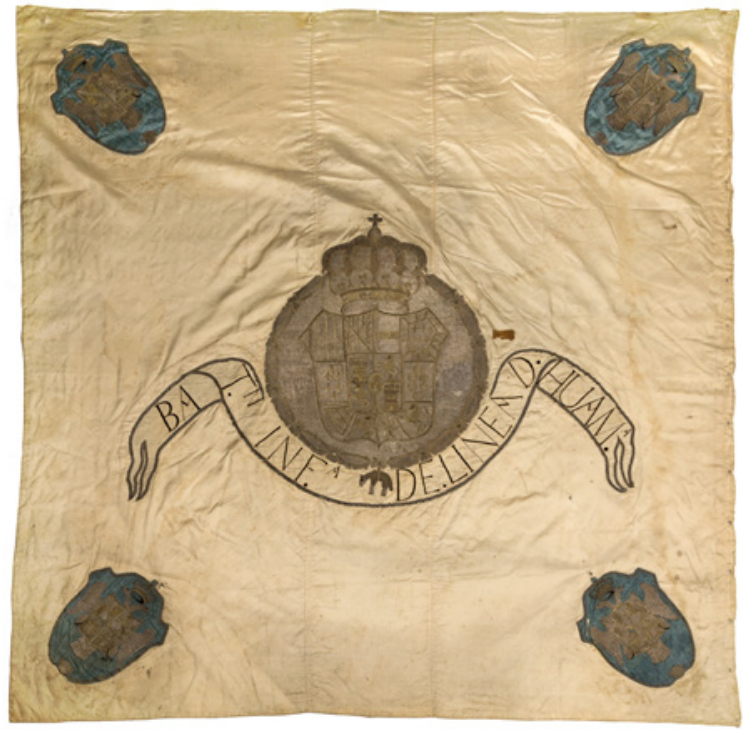

$\bullet \quad$ FIGURA 8 .

Autor desconocido. Bandera española del Batallón de infantería de la Línea de Huamanga, tomada en la campaña de independencia del Perú, ca. 1824

Fuente: Museo Nacional de Colombia, registro I02

Con ellas fue decorado un salón para un baile en honor al Libertador. Finalmente, el $\mathrm{I}^{\circ}{ }^{\mathrm{d}}$ de noviembre de 1825 se hizo una procesión solemne para su traslado del Palacio de Gobierno al Museo (Santander 357; Rojas) ${ }^{\mathrm{I}}$. Con motivo del traslado, el poeta y diplomático José Fernández de Madrid (I789-1830) compuso un soneto:

Estas son las banderas que algún dia

Los fieros Castellanos tremolaron;

Estas en Cajamarca presenciaron

La mas abominable alevosía;

Recuerdos de opresión y tiranía,

Al Perú tres centurias insultaron,

Y los Libertadores las hallaron

Tintas en pura sangre todavía.

¡Monumentos de un déspota insolente,

Banderas de Pizarro ensangrentadas,

I Agradezco a María Paola Rodríguez Prada, curadora de Historia del Museo Nacional de Colombia, la referencia de Francisco de Paula Santander. 
Que rindió ante Bolívar la Victoria:

A los pies de Colombia independiente

Para Siempre abatidas y humilladas,

Oprobio del Perú, sed nuestra gloria! (Fernández de Madrid, "A las banderas españolas”; Fernández de Madrid, “A las banderas de Pizarro”)

En época de la República, el estandarte volvió a ser llevado en solemne procesión, pero ya no para recordar la autoridad de la monarquía sino para mostrar la victoria del régimen independiente; ya no con destino a una iglesia, sino al mausoleo republicano, esto es, el museo.

Un recibimiento similar tuvo el estandarte que Bolívar remitió a Venezuela. Tras ser recibido en Caracas el 26 de febrero de I826 (Rojas 306), el estandarte atribuido a Pizarro fue llevado por una comitiva que lo arrastró por la calle "para significar así el odio contra nuestros antiguos mandatarios". Pasaría al olvido por casi dos décadas hasta que fue nuevamente recuperado y depositado en el mausoleo destinado a guardar las cenizas del Libertador, repatriadas de la Nueva Granada a Venezuela en I842 (Rojas 4I).

El estandarte de Pizarro, un símbolo de opresión y libertad, desde su recibimiento en el museo fue considerado una pieza representativa de la independencia nacional. Los visitantes extranjeros que dejaron memorias de su visita por el museo atestiguan esta condición. Así, el viajero francés Auguste Le Moyne (I800-I880), en su obra Viajes y estancias en América del Sur, narra su visita a Colombia entre I828 y 1829 y menciona sobre el Museo de Bogotá: "De los objetos más curiosos eran ejemplares minerales, armas, fetiches y cacharros de los primitivos indios, algunos cuadros de Vásquez y finalmente el estandarte del conquistador Pizarro donado por el Perú a Bolívar” (Le Moyne ing). También lo refirió el diplomático brasileño Miguel María Lisboa (I809-I88I) quien visitó la Nueva Granada y el Museo en I853:

En las vitrinas que ya mencioné hay una colcha de plumas, obra de los indios andaquíes, y una bandera de damasco bordada en oro que, como la que existe en Caracas, perteneció a Pizarro y fue traída de Lima por Bolívar; y en las columnas que sostienen el techo de la sala están colgadas varias banderas tomadas en la guerra de la independencia. (Lisboa 2II)

Lisboa, que había desempeñado funciones como diplomático del Brasil en Venezuela, conoció el estandarte que reposa en Caracas y no dudó en afirmar que ambos pertenecieron a Pizarro. 
El estandarte real de Castilla atribuido a Pizarro fue recibido en el museo como un trofeo de guerra que significó varias cosas a un mismo tiempo. Sobre el objeto se operó una yuxtaposición de significados por su consideración como principal símbolo de la monarquía española y del orden social que esta impuso en América. Asimismo, era un representante de la pérdida de la libertad utópica del indígena prehispánico. No obstante, de manera paradójica, también era un símbolo distintivo de la victoria definitiva de la nueva república sobre el régimen monárquico. Se trató de una representación ostensible de un cambio en la autoridad local. Las élites políticas en época republicana manifestaron su poder con la destrucción simbólica y a menudo literal del estandarte. El acto de destrucción significó de forma eufemística un cambio del poder que estaba concentrado en el rey y que ahora pasaba al pueblo. Dicho de otro modo, simbolizó un paso de élites extranjeras a élites criollas.

\section{El estandarte como memoria del pasado de las élites nacionales}

Durante las décadas posteriores a la independencia el estandarte permaneció en las colecciones del museo sin suscitar mayor atención. A partir de la segunda mitad del siglo xix se impuso una nueva élite gobernante que reemplazó a las primeras autoridades de la nación, posicionadas después del logro de la independencia. Siguiendo la clasificación de Campagne antes referida sobre la formación de la simbólica nacional en los países latinoamericanos, sería esta nueva generación, educada tras el desmonte definitivo de las instituciones políticas y económicas coloniales, lejana del fantasma de una posible reconquista europea, la que reinterpretaría el orden social y sus símbolos forjadores presentando una interpretación del estandarte que se mantendrá hasta finales del siglo xx.

Tras el golpe de Estado de José María Melo (I80o-I860) en I854, representante del artesanado, porción de la población de origen humilde, las élites gobernantes dejaron a un lado sus diferencias y se unificaron para reivindicar su derecho a gobernar como herederos de las principales familias de la nación, aquellas que habían ocupado los más altos cargos desde la época colonial (Palacios y Safford 38I y ss.). La desconfianza de las élites respecto del pueblo, que antes fue el aliado que luchó codo a codo la independencia, transformó el ideario de las élites políticas y económicas nacionales, a la vez que suscitó una 
nueva interpretación de los tradicionales símbolos en los que se fundamentaba un sentimiento nacional.

Merced a este cambio de valoración social operado desde la cabeza de la nación, a partir del último tercio del siglo xix hasta el primero del siglo xx, el estandarte volvió a recibir amplia atención. Autores de diversas nacionalidades indagaron por la originalidad de las distintas versiones del estandarte. En I872 el escritor peruano Ricardo Palma (I833-1919) inició la publicación de una recopilación de noticias históricas: Tradiciones peruanas. En el tomo segundo aparece el artículo: "Tres cuestiones históricas sobre Pizarro", en el cual aborda el problema de la autenticidad del estandarte de Lima y llega a una conclusión negativa (Palma i83 y ss.). Palma asegura que el estandarte real con el que Pizarro entró en Cuzco en 1533 tenía un Santiago Matamoros bordado al respaldo.

En el mismo año de la publicación de Palma, en Caracas se llevó a cabo una "procesión cívica" en la que un grupo de personas que representaba a la "España oficial y privada” portó nuevamente el estandarte que estaba guardado en la tumba de Simón Bolívar. Durante la procesión se descubrió que el estandarte tenía bordado en la parte posterior al escudo de Castilla, un caballero enarbolando una espada, ícono que luego se atribuyó a Santiago Matamoros (Rojas I5). Con motivo de este descubrimiento, Arístides Rojas (I826-1893), médico, naturalista e historiador venezolano, escribió largamente sobre el estandarte de Caracas y lo comparó con los demás estandartes atribuidos a Pizarro. Su primera publicación al respecto data de 1876 y allí desarrolla una argumentación que repite con algunas variaciones en sus otros escritos. Con base en correspondencia de José Antonio de Sucre y oficios de los gobiernos de la Nueva Granada y Venezuela, Rojas concluye que el verdadero estandarte de Pizarro se encontraba en Caracas, que el estandarte de Perú era el estandarte real de Lima, en tanto que el de Colombia era otro estandarte real de Castilla en Cuzco. La prueba definitiva la encontró en la publicación de Palma, que consideró evidencia suficiente para concluir con la autenticidad del estandarte de Caracas.

Que ambos autores coincidieran en el mismo tema alrededor de la misma época obedecía a un renovado interés latinoamericano por la cuestión del pasado Español americano. Merced a esta consideración, Rojas juzgó el estandarte de una nueva forma:

El estandarte de Pizarro no es un trofeo de guerra; es un recuerdo de familia, un orgullo de raza, una época inmortal; es el símbolo de unión entre dos grandes pueblos de igual origen y de comunes glorias. (Rojas 42) 
Ya no un trofeo de guerra arrebatado a unos despiadados dominadores, tal como en épocas pasadas se lo consideró, sino un vínculo de hermandad racial, cultural e histórica. La consideración de Rojas hacia España y el pasado hispanoamericano hacía parte de un movimiento generalizado en Latinoamérica según el cual las élites políticas y culturales pasaron a identificarse no ya con el idílico indígena, sino con el conquistador. Este movimiento, conocido como el panhispanismo, en términos generales planteó la idea de una comunidad racial compartida por las élites de los países que un día pertenecieron a la Corona de España (Pérez) ${ }^{2}$.

En Colombia las ideas de la hispanofilia arraigaron por esa misma época. Un ejemplo de aquellas nuevas ideas se plasmó en la literatura conocida como costumbrista, un género que se desarrolló en comunión con esta ideología y que fue cultivado por autores que a un tiempo eran gobernantes y representantes de la cultura nacional. Esta literatura predicaba una nostalgia por las costumbres heredadas de la Colonia, criticaba los extranjerismos y señalaba con acritud a aquellos que sin pertenecer a familias de abolengo pretendían escalar socialmente gracias a las nuevas consideraciones sociales del liberalismo (Martínez 190).

La rehabilitación de la tradición por sobre las nuevas ideas francesas o alemanas que se importaban en la época, además de la literatura también se expresó en otros frentes de la cultura. Tras la rebelión de los artesanos en cabeza del general Melo en I854 se presentó una suerte de necesidad de las élites de consolidar política y culturalmente su lugar en la sociedad, ya fuera por las armas, o mediante la creación y reinterpretación de los símbolos que representaban la nación. Así, el poder político de las élites debería hallar su fundamento simbólico en los comienzos mismos de la nación.

La primera publicación que abordó el problema de la autenticidad del estandarte que se encuentra en las colecciones del Museo Nacional de Colombia fue la del educador Ernesto León Gómez (m. I892), publicada en I882. El artículo, titulado "El estandarte de Francisco Pizarro", defendía la autenticidad del estandarte real que se encontraba en Bogotá, para lo cual se basaba en un oficio firmado por el secretario del Interior de Colombia José Manuel Restrepo

2 Sobre el panhispanismo en Colombia véase Martínez.

3 Publicado originalmente en el periódico El Bogotano, posteriormente transcrito en el Boletín de Historia y Antigüedades (vol. 2, n. ${ }^{\circ}$ 24, pp. 716-725). 
(I78I-1963) ${ }^{4}$. En este documento se daba la orden de trasladar las banderas del palacio al museo el in de noviembre de I825. Esta afirmación de autenticidad excluía la documentación de Bolívar publicada a partir de I879 en las memorias de Daniel Florencio O’Leary (I8OI-I854), documentación que mostraba que Bolívar había destinado el estandarte real de Pizarro a Caracas. Asimismo, descartaba los artículos de Arístides Rojas y de Ricardo Palma. Sin embargo, León Gómez compartía con ambos la consideración sobre el estandarte. En su texto afirma que este

era la prueba más elocuente de la grandeza de la revolución que su espada [la de San Martín] había completado; era la asociación de su nombre al del conquistador del Perú, en las páginas perdurables de la historia. (Gómez 717)

Se trataba de un trofeo que asociaba la élite independentista con el poder conquistador. Unos años después, Pedro María Ibáñez (I854-I919), quien luego sería presidente de la Academia Colombiana de Historia, retomó el tema en un apartado de su libro Crónicas de Bogotá y sus inmediaciones, publicado en I89I. Ibáñez, que conocía toda la documentación presentada por Rojas, continuó defendiendo la autenticidad del estandarte de Bogotá. Entre sus evidencias estaba el documento antes referido por León Gómez, además de un testimonio sobre una recepción dada en Bogotá el I5 de noviembre de I826. La recepción había sido ofrecida a diplomáticos de México, Inglaterra y Estados Unidos, y en ella se utilizó el estandarte para adornar la estancia. Según Ibáñez, el diplomático de México dejó constancia de que: "Entre los distinguidos trofeos de las armas de Colombia se ven en esta capital el estandarte real de Pizarro y la diadema de la última princesa de los Incas, enviados por el joven e intrépido Sucre, desde la antigua ciudad de Mancocapac" (Ibáñez 272). Sobre la "diadema de la última princesa de los Incas", no hay registro en las colecciones del Museo. Es posible que el diplomático confundiera el nombre con El accso de la reina mujer de Atahualpa, una pieza del Museo Nacional que donó Antonio José de Sucre en 1825 (número de registro 205). No es claro por qué Ibáńez presenta como evidencia de autenticidad un testimonio equívoco. Al parecer, antes que la contundencia de

4 León Gómez señala que la correspondencia citada se encuentra en el archivo del Colegio Mayor de San Bartolomé. Sin embargo, en el desarrollo de esta investigación se revisó la sección del archivo que es posible consultar y entre los documentos no se encontró este oficio. 
las evidencias, era más importante para los colombianos la afirmación de la originalidad del estandarte a toda costa.

A finales del siglo xIx, un cambio ideológico en los detentores del capital cultural generó una nueva valoración del estandarte atribuido a Francisco Pizarro: ya no se trató de un trofeo de guerra, ahora era un objeto que religaba dos épocas y dos élites gobernantes, que confería autoridad a quienes dirigía con su aura de poder.

\section{El estandarte de Pizarro: las valoraciones cambiantes de un mismo objeto}

El estandarte real que reposa en las colecciones del museo, desde su llegada como trofeo de guerra ha sido considerado una pieza insigne por su poderoso contenido simbólico. En términos contemporáneos, es considerado patrimonio de la nación y hace parte de los objetos con los que se recuerda la gesta que concluyó en la independencia nacional. Sin embargo, siendo las élites económicas y políticas las que por su formación y medios han manipulado los símbolos e interpretado y comunicado su significado al grueso de la población (García 79), el análisis del sentido de un símbolo de poder, como el estandarte real, es también una investigación de los asideros ideológicos sobre los cuales se fundamentó el poder y la autoridad local.

De esta forma, la historia del estandarte real de Pizarro durante la época de dominio de la Corona española implicó la representación de la autoridad misma del rey. El ritual en el cual era exhibido constituía una aceptación del poder real, a la vez que una legitimación de los poderes locales involucrados en la ceremonia. Tras la independencia, las nuevas autoridades criollas, necesitadas de símbolos nuevos o de la reinterpretación de los preexistentes, justificaron el traspaso de sentido del estandarte, convertido entonces en un símbolo de la victoria patriota y la derrota del rey ausente. Durante la segunda mitad del siglo XIX, cuando la gesta de independencia ya era historia patria, y el ambiente político y cultural que pregonaba el ideal de un Estado compuesto por individuos iguales ante la ley había pasado, el estandarte fue utilizado como un símbolo de conexión entre dos poderes unidos por lazos de parentesco. 
Toda esta transformación de sentido del estandarte operada durante siglos muestra cómo este fue un recurso utilizado por las élites políticas para legitimar o deslegitimar su relación con el pasado y con ello fundamentar de diversas formas su raigambre histórica. Se trata de un objeto culturalmente institucionalizado que como símbolo fácilmente asimilable por el pueblo, se develó de mayor utilidad para la configuración de un discurso político generalizado.

El estandarte de Pizarro es un objeto museal que por su antigüedad en las colecciones del museo, porque su historia está íntimamente ligada a la historia misma de la nación, muestra patentemente que los símbolos con los que se ha representado la nación han sido instituidos como sólidos asideros de un sentimiento nacional perenne, pero que en el fondo su sentido se renueva continuamente según las ideologías e intereses de quienes tienen el capital cultural para interpretarlos y comunicar su sentido.

\section{3 \\ $\begin{array}{llllllllllll}\text { B I } & B & L & I & \mathbf{O} & G & \mathbf{R} & \mathbf{A} & \mathbf{F} & \mathbf{I} & A\end{array}$}

\section{F U E N T ES PR I MA R I A S}

\section{A. Archivos}

Archivo General de la Nación, Colombia (AGN)

Fondo Colonia $(F C)$

Milicias y Marina (MM) leg. II9, ff. I00I-1005, I790.

Cabildo del Socorro. "Informe sobre los regocijos públicos que hubo, con motivo de la proclamación de Carlos IV”.

\section{B. Impresos}

Caballero, José María. Diario de independencia. Bogotá: Talleres Gráfico Banco Popular, 1974.

Consejo de Indias. Recopilación de leyes de los Reynos de la Indias, vol. Ir. Madrid: Andrés Ortega, 1774 .

Fernández de Madrid, José. “A las banderas españolas colocadas en el museo de Bogotá”. Gaceta de Colombia (1825), trim. 17, n. ${ }^{\circ} 213$. 
---. “A las banderas de Pizarro colocadas en el museo de Bogotá”. El Constitucional (1825), n. ${ }^{\circ} 62$.

Gómez, León. "El estandarte de Francisco Pizarro". Boletín de Historia y Antigüedades, vol. 2, n. ${ }^{\circ} 24,1904$, pp. 716-725.

Gual, Pedro. "A S. E. el jeneral en jefe Antonio José de Sucre comandante en jefe del ejército de Colombia auxiliar al Perú". Gaceta de Colombia (I825), trim. 15, n. ${ }^{\circ} 192$.

Ibáñez, Pedro María. Crónicas de Bogotáy sus inmediaciones. Bogotá: Imprenta de la Luz, I98I.

Le Moyne, Aguste. Viajes y estancias en América del Sur, la Nueva Granada, Santiago de Cuba, Jamaica y el Istmo de Panamá. Bogotá: Biblioteca Popular de Cultura Colombiana, 1945.

O’Leary, Florencio. Memorias. Caracas: Imprenta de “El Monitor”, I884.

Palma, Ricardo. Tradiciones peruanas. Cuarta Serie. Tomo II. Barcelona: Montaner y Simón, I893.

Rojas, Arístides. El estandarte de Pizarro. De la colección de leyendas históricas de Venezuela. Caracas: Imprenta de la Patria, 1892.

---. Libro en prosa. Caracas: Rojas Hermanos Editores, 1876.

---. Objetos históricos de Venezuela en la exposición de Chicago. Estudios acerca de ellos. Caracas: Imprenta y Litografía Nacional, I893.

Santander, Francisco de Paula. Cartas y mensajes del general Francisco de Paula Santander, vol. v. Compilado por Roberto Cortázar. Bogotá: Banco de la República, 1954.

Sucre, Antonio José de. "Perú. Ejército colombiano de la República peruana”. Gaceta de Colombia (1825), trim. I5, n. ${ }^{\circ}$ I91.

---. “Al señor secretario de estado del despacho de la guerra \& \&”. Gaceta de Colombia (I825), trim. $17, n .^{\circ} 203$.

Vargas Jurado, José Antonio. La Patria Boba. Bogotá: Imprenta Nacional, 1902.

\section{F U E N T ESSECUNDARIAS}

Appadurai, Arjun. "Introducción: las mercancías y la política del valor". La vida social de las cosas. Perspectiva cultural de las mercancías. Ciudad de México: Grijalbo, I991, pp. 17-87.

Baca Plascencia, Francisco. "El paseo del pendón de la ciudad de México en el siglo Xvi". Tesis de maestría en Historia, Universidad Iberoamericana, México, 2009.

Bourdieu, Pierre. "Los tres estados del capital cultural". Sociológica, n. ${ }^{\circ}$, 1987, pp. II-I7. 
Campagne, Fabián Alejandro y José Emilio Buraca. "Mitos y simbología de la nación. Los países del Cono Sur". De los imperios a las naciones: Iberoamérica, editado por Antonio Annino, Luis Castro Leiva y François Xavier Guerra. Zaragoza: Caja de Ahorros y Monte de Piedad de Zaragoza, 1994, pp. 349-381.

Earle, Rebeca. "La iconografía de la Independencia en la Nueva Granada”. Cartagena de Indias en la Independencia, editado por Haroldo Carlo Stevenson y Adolfo Meisel-Roca. Bogotá: Banco de la República, 2011, pp. 561-598.

García Canclini, Néstor. "Los museos en la desglobalización”. Revista Museos, n. 35, 2016, pp. 76-86.

Giraudo, Laura. “Conquista y constitución: el paseo del real pendón en la ciudad de México

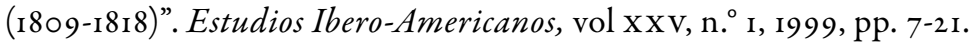

Henao Albarracín, Ana María. “Ceremonias reales y representación del rey. Un acercamiento a las formas de legitimación y propaganda del poder regio en la sociedad colonial neogranadina. Cali s. XVIII". Historia y Espacio, n. ${ }^{\circ}$ 32, 2009, pp. I-19.

Lisboa, Miguel María. Relación de un viaje a Venezuela, Nueva Granada y Ecuador. Bogotá: Fondo Cultural Cafetero, 1984.

Lomne, Georges. "Las ciudades de la Nueva Granada: teatro y objeto de los conflictos de la memoria política". Anuario Colombiano de Historia Social y de la Cultura, n. ${ }^{\circ}$ I, I993, pp. II 4-I35.

Majluf, Natalia. "Los fabricantes de emblemas. Lo símbolos nacionales en la transición republicana. Perú, I820-I825”. Visión y símbolos. Del virreinato criollo a la república peruana, por Ramón Mujica. Lima: Banco de Crédito del Perú, 2006, pp. 202-24I.

Martínez, Frederick. El nacionalismo cosmopolita. La referencia europea en la construcción nacional en Colombia, I845-19oo. Bogotá: Banco de la República; Instituto Francés de Estudios Andinos, 200 I.

Palacios, Marco y Frank Safford. Colombia: pais fragmentado, sociedad dividida: su historia. Bogotá: Grupo Editorial Norma, 2002.

Pérez Monfort, Ricardo. Hispanismo y falange. Los sueños imperiales de la derecha española y México. México: Fondo de Cultura Económica, 1992.

Pita Pico, Roger. Celebraciones politicas y militares en Colombia: de virreyes y monarcas al santoral de la patria. Bogotá: Academia Colombiana de Historia, 2016.

Sánchez Paredes, Libardo. "El Estandarte de Pizarro en el Museo Nacional de Colombia: fuentes primarias de un ícono de la Independencia". Cuadernos de Curaduría, n. ${ }^{\circ}$ is, 2019, pp. 180-199.

Vanegas, Isidro. Las batallas de Boyacá. Hombres, mujeres, experiencias. Tunja: Ediciones Plural, 2019. 